\title{
A comparative study of corneal incisions induced by diamond and steel knives and two ultraviolet radiations from an excimer laser
}

\author{
JOHN MARSHALL,' STEPHEN TROKEL,' STEPHEN ROTHERY,' \\ AND RONALD R KRUEGER'
}

From the 'Institute of Ophthalmology, Judd Street, London WC1H $9 Q S$, and the ${ }^{2}$ Edward S Harkness Eye Institute, Columbia-Presbyterian Medical Center, 635 West 165th Street, New York, NY 10032, USA

\begin{abstract}
SUMMARY This paper reviews the potential role of excimer lasers in corneal surgery. The morphology of incisions induced by two wavelengths of excimer laser radiation, $193 \mathrm{~nm}$ and $248 \mathrm{~nm}$, are compared with the morphology of incisions produced by diamond and steel knives. Analysis suggests that ablation induced by excimer laser results from highly localised photochemical reactions and that $193 \mathrm{~nm}$ is the optimal wavelength for surgery. The only significant complication of laser surgery is loss of endothelial cells when incisions are within $40 \mu \mathrm{m}$ of Descemet's membrane.
\end{abstract}

Excimer lasers may herald a new epoch in surgery of the cornea. The term excimer is derived from the first two and last syllables of the words that describe the physical state of the lasing media used in such lasers-excited dimers of inert gases. Excited dimers are two atoms of an inert gas bound in a highly excited state with atoms of halogen to form a temporary association as a diatomic rare gas halide. The decay of these unstable molecules is accompanied by the emission of a highly energetic photon of ultraviolet light. Excimer lasers are systems whose emission wavelengths are variable and determined by a specific energy transition, characteristic of the particular gases used to fill the lasing cavity. For example the emission for argon fluoride occurs at $193 \mathrm{~nm}$, and that for krypton fluoride at $248 \mathrm{~nm}$. They emit their radiation as a train of individual pulses whose duration is typically about 10 nanoseconds, and with a pulse repetition frequency of between 5 and $15 \mathrm{~Hz}$.

Interest in their surgical potential was initiated by reports from scientists in both the materials and electronic industries that the intense ultraviolet radiation emitted by such lasers could be used to etch submicron patterns into the surfaces of plastics and other polymers ${ }^{2}$ with a remarkable degree of accuracy and with no degradation processes being conducted to unirradiated areas. ${ }^{34}$

Correspondence to Professor J Marshall.
The discrete focal localisation of the effects induced in target materials is currently under investigation. Two theories have been proposed. The first of these proposes that beam tissue interactions are predominantly the result of ultrafast thermal events, or so called photon-phonon interactions, and that the discrete nature of the induced change arises because of the very short penetration or adsorption depth of the ultraviolet radiation. ${ }^{5}$ The second theory asserts that the target reaction is not thermal but probably photoablation, or photon-induced molecular decompensation. ${ }^{67}$ The protagonists of photoablation suggest that molecules in the target area are released as a direct result of rupture of intermolecular bonds whose uncoupling is induced by absorption of high energy photons. Such a mechanism is possible, because in the ultraviolet spectrum individual photon energies are in excess of 6 electron volts and are thus capable of disrupting valency electrons. Thus only those molecules that absorb ultraviolet radiation directly are affected, and adjacent areas would show no conductive effects. It is suggested that, once molecules have been disrupted, the small, energetic, and volatile fragments rapidly ablate. This mode of action would produce the sharply defined boundaries of irradiated areas. It could also account for the smooth surface of the substrata exposed by surface erosion during excimer irradiation, with the total depth of the erosion being 
a function of the absorption depth at any given wavelength an the duration of the exposure.

The concept of photoablation with its implicit precision has provoked the initiation of a number of pilot studies involving irradiation of biological tissues. ${ }^{x}$ Early results with high resolution troughs or trenches being eroded in such tissues as human hairs inspired Trokel to collaborate with Srinivasan and others to examine the potential of excimer lasers for corneal surgery. ${ }^{\prime}$

The present paper examines the erosions induced by two different wavelengths of ultraviolet light and attempts to consider the optimal factors for potential clinical use. In addition ultrastructural changes induced by lasers are compared with those generated by conventional instruments.

\section{Methods and materials}

\section{LASER STUDIES}

The laser used throughout the present study was a Model 102E Excimer laser produced by Lambda Physik (Gottingen, West Germany). The cavity was filled, to the manufacturers' recommended levels, with either argon and fluorine or krypton and fluorine gases in order to provide emissions at $193 \mathrm{~nm}$ or 248 $\mathrm{nm}$ respectively. Given both the practical problems and the expense of changing gases, experiments at the two different wavelengths were performed as a sequential series rather than consecutive individual exposures of alternating wavelengths. The laser was modified so that the cavity was configured as an unstable resonator, and this produced a marked decrease in the far field divergence of the emergent beam.

The laser output was shaped with a $15 \mathrm{~mm}$ quartz cylindrical lens and passed through a $15 \times 3 \mathrm{~mm}$ aperture placed adjacent to the cylindrical lens. The convergent beam was focused directly on to the specimen target. At the focus the laser produced a sharp rectilinear image some $21 \mathrm{~mm}$ long. At $193 \mathrm{~nm}$ the total output of this laser was $80 \mathrm{~mJ}$, but this was reduced to a maximum of $20 \mathrm{~mJ}$ after passing through the collimator and aperture. The output at $248 \mathrm{~nm}$ was significantly higher with values of up to $100 \mathrm{~mJ}$ and $50 \mathrm{~mJ}$ in comparable locations. The duration of individual pulses within the pulse train also varied with wavelength, being about 14 nanoseconds with argon fluoride and 9 ns in the case of krypton fluoride. One further variable is the rate at which the peak power is reached in any given pulse at the two different wavelengths.' There is a marked substructure in excimer laser pulses, and this may be of importance in analysing induced biological effects.

The laser was run at pulse repetition frequencies of either 3,5 , or $10 \mathrm{~Hz}$ and exposure durations were of
$5,8,10,15,30$, or 45 seconds. The higher frequencies and longer exposures were generally used at $193 \mathrm{~nm}$, giving fluence or dose values of 150,300 , and 450 $\mathrm{mJ} / \mathrm{cm}^{2}$. These exposure parameters were derived from previous experiments where it was calculated that $1 \mathrm{~J} / \mathrm{cm}^{2}$ at $193 \mathrm{~nm}$ ablates corneal tissue to a depth of $1 \mu \mathrm{m} .{ }^{y}$ It was hoped that this range of doses would provide specimens with a variety of depths of incisions, including full penetration of the cornea.

Fourteen albino rabbits each weighing about $2 \mathrm{~kg}$ were anaesthetised with intravenous phenobarbital. The animals were placed on a positioning board with the target eye held open with a lid speculum and the cornea centred at the focus of the laser delivery system. A vertical or horizontal incision was made on the cornea of each eye. The laser was imaged in such a way that the resultant incision extended over the limbus. Six of the animals were exposed to radiation at $193 \mathrm{~nm}$ and eight to $248 \mathrm{~nm}$. All animals were killed between 5 and 30 minutes after exposure with an intravenous overdose of phenobarbital.

\section{CONVENTIONAL INCISIONS}

Four rabbits of similar size and weight were anaesthetised in an identical manner. Each eye was prepared and draped and one eye of each animal was incised by a steel blade and the other by a diamond knife. Two of the animals received incisions in the vertical plane and two received them in the horizontal meridian. All incisions were made by a single pass of the cutting instrument across the central cornea, and pentrating to between one-half and one-third of the corneal thickness. A new Sharpoint microsurgical blade was used for each of the steel knife incisions, and those of diamond were performed with a new trifaceted Micra diamond knife.

\section{HISTOLOGY AND ULTRASTRUCTURE}

Immediately after death the eyes were removed, and a $5 \mathrm{~mm}$ penetrating incision was made at the ora serrata before the globes were placed in $3 \%$ glutaraldehyde buffered in Earl's buffer at $4^{\circ} \mathrm{C}$. After 24 hours in this initial fixative the eyes were examined under a dissecting microscope, and corneal samples were isolated and divided such that each site of irradiation or conventional incision could be processed for examination by both scanning (SEM) and transmission (TEM) electron microscopy.

Specimens for SEM were postfixed overnight in $2 \%$ osmium tetroxide buffered in $0.1 \mathrm{M}$ sodium cacodylate. They were dehydrated through a series of ascending concentrations of acetone in water before being critical-point dried (Emscope CPD 750). Dried samples were coated with a $30 \mathrm{~nm}$ layer of gold in a sputter coater (Emscope SC 500) prior to being 
examined in either a Hitachi 510 or 520 scanning electron microscope.

For TEM, specimens were postfixed for only 1 hour in the osmium tetroxide solution described above, dehydrated in alcohol, and then embedded in Araldite (CY212) via epoxypropane. Sections were cut at $1 \mu \mathrm{m}$ on glass knives for light microscopy (LM) and on diamond knives in a Reinchert OMU4 ultramicrotome for electron microscopy. Sections were mounted on 200 mesh copper grids, and stained with uranyl acetate and lead citrate before being examined in an AE1 801 transmission electron microscope.

\section{Results}

As anticipated, the range of exposure parameters used in the laser studies resulted in a variety of depths of erosions with several through-and-through incisions at each of the two wavelengths. The most striking feature of laser induced incisions was the focal definition and the rigidly parallel nature of the smooth edges of troughs ablated by argon fluoride emissions at $193 \mathrm{~nm}$ (Fig. 1a). These were in stark contrast to erosions induced by the krypton fluoride emissions, where, although the boundaries were smooth, adjacent tissue damage was irregular and diffuse (Fig. 1b), as were those of incisions produced by both diamond (Fig. 1c) and steel knives (Fig. 1d). All wounds in the corneal stroma regardless of mode of induction resulted in a marked swelling with stromal thickness increased by up to one-third when compared with adjacent areas (Fig. 1).

The appearance of non-penetrating incisions was directly related to their mode of induction. Where argon fluoride emissions fell normal to the corneal surface, flat bottom troughs of varying depth were eroded (Fig. 2a). However, when the radiation struck the cornea obliquely, $\mathrm{V}$-shaped grooves were apparent. Erosions by krypton fluoride were characterised by a zone of debris which had a peculiarly smooth surface (Fig. 2b). This debris covered the entire area of irradiation in superficial wounds, or both edges of the wound in cases of deep ablation. In appearance the smooth surfaced zone looked analogous to a condensed or solidified mass of previously molten material like metal running from a smelting furnace or lava from a volcano. Diamond knife incisions were seen as fine linear slits whose edges were closely appositioned (Fig. 2c), while those created by steel were V-shaped with gaping and irregular margins (Fig. 2d).

In all penetrating incisions induced by either wavelength of the laser the total ablation of intervening tissue resulted in the complete occlusion of the incision as the two walls collapsed and came to lie in anatomical juxtaposition.

\section{THE EPITHELIUM}

SEM preparations demonstrated one of the practical limitations of the crude delivery system used for the laser studies-that of presenting a repetitively pulsed exposure of several seconds' duration to a target capable of involuntary movement. In several experiments eye movements had occurred during the laser exposure and resulted in consecutive pulses falling on different target locations. Such specimens showed a series of parallel superficial excorations where varying numbers of epithelial cells had been debrided. The surface topography of these grooves differed with wavelength of the causal radiation, while the depth varied with the effective exposure duration, that is, the number of laser pulses falling on any given area.

\section{Argon ftuoride laser irradiation $(193 \mathrm{~nm})$}

At this wavelength all areas of ablation showed epithelial damage with the respective edges of the wound having curved margins such that, when they were measured at right angles to the axis of the incision, the width of the damage in the surface cell layer was always greater than that in the layer of basal cells (Fig. 3a). These curved margins were considered to have arisen through the release of elastic tension within the surface layers of the epithelium.

On SEM, surface cells adjacent to the margins of the trough had irregular boundaries, but the damage zone was confined within the dimensions of a single surface cell on each border.

\section{4}

Fig. 1 Light micrographs of rabbit corneas incised by (a) an argon fluoride excimer lasr (193 nm); (b) a krypton fluoride excimer laser (248 nm); (c) a Micra diamond knife; (d) a Sharpoint steel blade. The bar markers are $100 \mu \mathrm{m}$.

Fig. 2 Scanning electron micrographs of the epithelial surface of rabbit corneas incised by (a) an argon fluoride laser (193 $\mathrm{nm}$ ); (b) a krypton fluoride laser (248 nm); (c) a Micra diamond knife; (d) a Sharpoint steel blade. In contrast to conventional incisions, in both laser induced kerfs the ablated surface is smooth. The broken cells in (a) (arrowed) are an artefact of preparation, and the red blood cells within the cleft came from severed limbal vessels. The bar markers are (a) (b) (d) $50 \mu \mathrm{m}$ and (c) $20 \mu \mathrm{m}$.

Fig. 3 Light (a, c) and electron (b, d) micrographs of incisions induced in the rabbit cornea by an argon fluoride excimer laser. The incised surface is extremely regular and bounded by a dense condensation or pseudomembrane (arrowed), which is particularly apparent in the stroma (c, d). The bar markers are (a) $50 \mu \mathrm{m}$, (b) $100 \mu \mathrm{m}$, (c) $20 \mu \mathrm{m}$, and (d) $1 \mu \mathrm{m}$. 


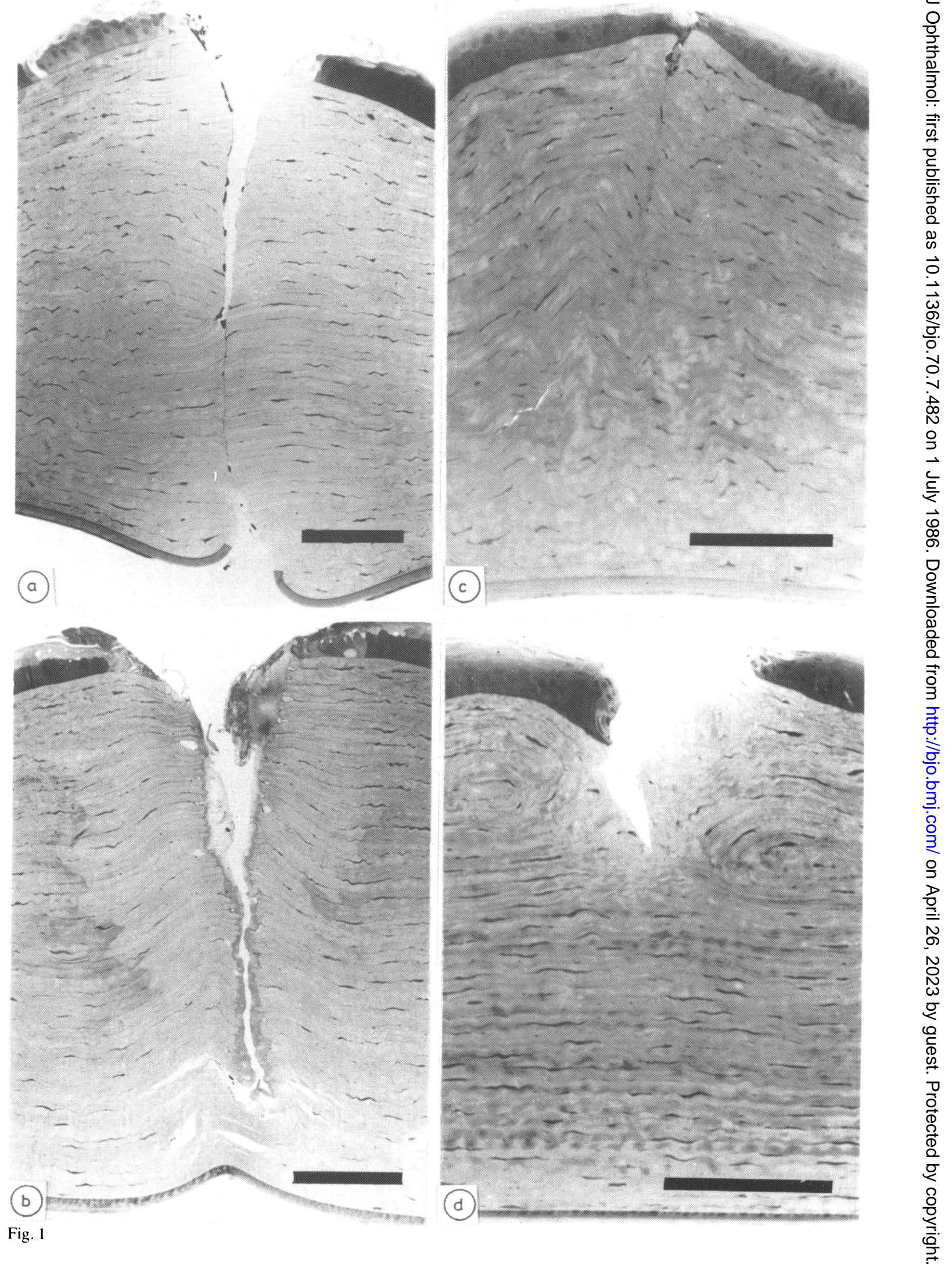



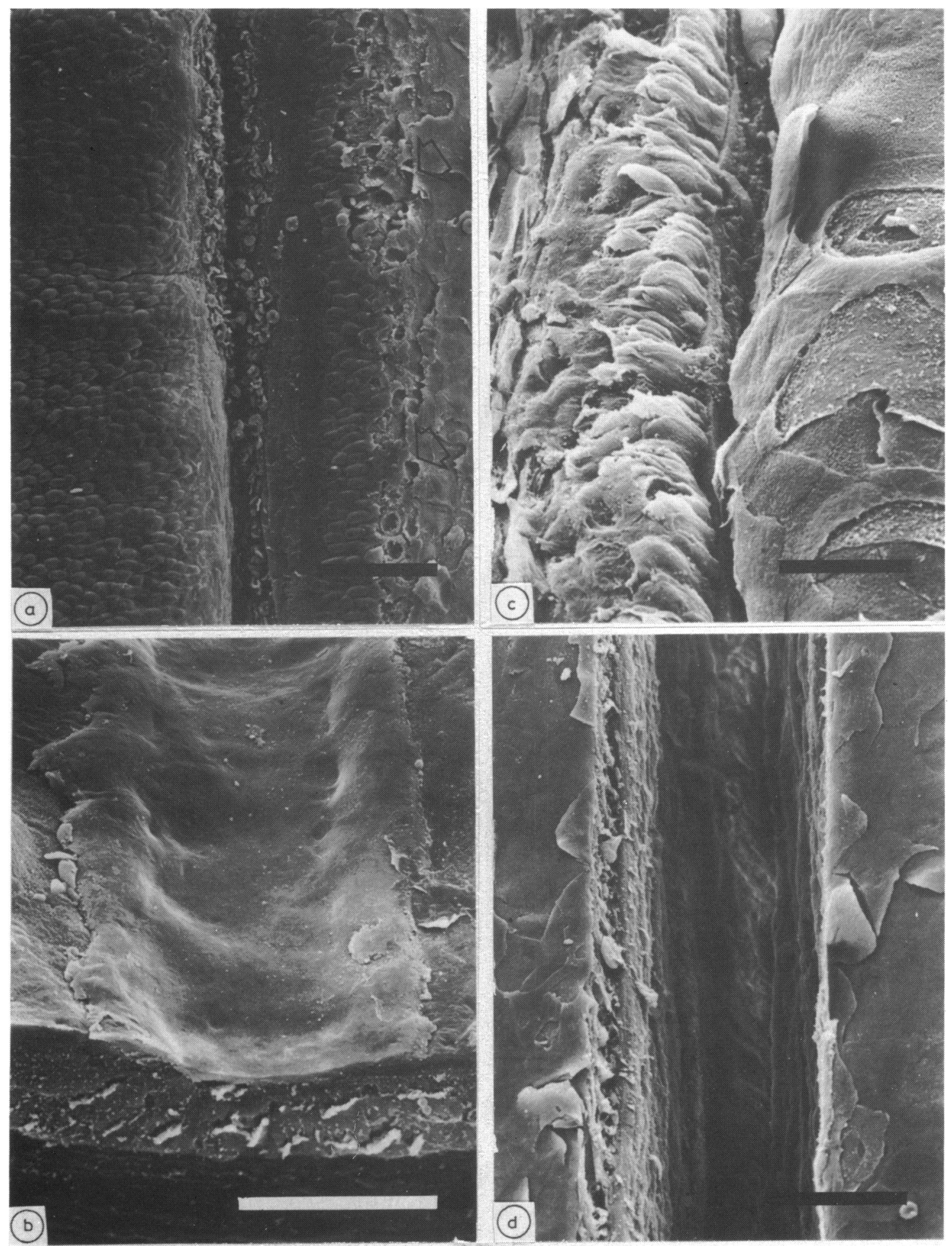

Fig. 2 

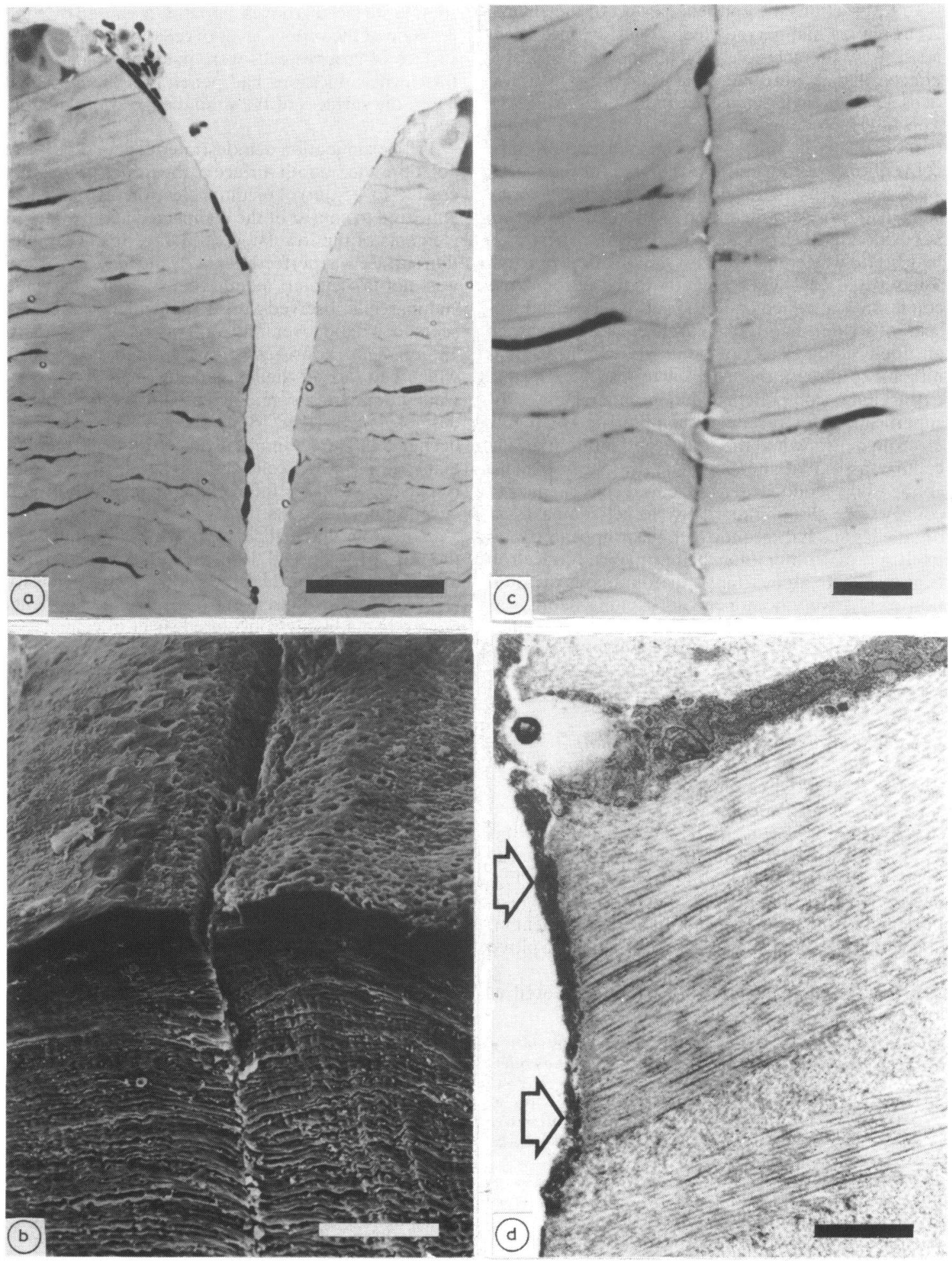

Fig. 3 
In $\mathrm{LM}$ sections the epithelial aspect of the ablated areas always had curved clean edges, with the cells nearest to the incision showing no demonstrable effects of damage other than staining slightly less densely than their immediate neighbours (Fig. 3). The interface between these cells and the ablated tissues seemed at this level of magnification to be a conventional cell membrane. This was deceptive, as TEM specimens demonstrated that the pale staining cells had no cell membrane on their aspect in apposition to the irradiated area (Fig. 4). These cells had literally been cleaved by the ablation process. The severed edge was bounded by an electron dense condensation, which had little substructure and was seldom greater than $100 \mathrm{~nm}$ in thickness. Given such an unphysiological set of boundary conditions it is difficult to discuss this zone in terms of intra- and extracellular components, but in general the most superficial or 'extracellular' component was highly electron dense, while the slight condensation on the cellular aspect of the boundary was less so. This condensed pseudoborder of cleaved cells seemed to convey some sort of integrity to the cell remnants, as organelles and background cytoplasm appeared relatively normal other than being atypically electron translucent. In all incisions a discontinuous distribution of relatively homogeneous staining debris was found on the epithelial surface at both margins. The only discernible substructure present in this amorphous mass was a series of ribbons of electron dense pseudomembranes like those described above.

\section{Krypton fluoride laser irradiation $(248 \mathrm{~nm})$}

The epithelial surface of areas adjacent to zones of krypton fluoride ablation was always covered by a smooth mass of tissue apparently congealed from a fused or fluid state (Fig. 5). The distal margin of this 'lava zone' was highly irregular, undulating like the margin of a wavelet dissipating itself on a beach (Fig. $5 \mathrm{~b}, \mathrm{c})$. The proximal margin became more irregular the deeper the ablation penetrated the epithelium, and within the basal layer it usually displayed a pitted or broken surface.

In LM sections superficial erosions appeared as smooth surfaced grooves, apparently caused by compression of the surface layer of cells. Just beneath the surface of grooves cells were pale staining. In contrast, where incisions had penetrated the epithelial layer, the surfaces of the wound edges were densely staining.

TEM examination demonstrated that in superficial ablations the smooth surface of the troughs was a thin crust ( 3 to $4.5 \mu \mathrm{m}$ ) of medium electron density which appeared to consist of the compacted and denatured elements of the irradiated cells (Fig. 4b). The ablation surface was perfectly smooth and featureless and was not a cellular membrane system. The pale staining cells observed with the light microscope were seen to extend over one or two cell layers ( 8 to $13 \mu \mathrm{m})$ and consisted of vacuolated cell ghosts which had lost all their organelles, but whose erstwhile boundaries were delineated by vestiges of the desmosomal system. Beneath the pale zone the deeper cells were abnormally electron dense, and in many cases these cells had pyknotic nuclei and displayed swollen intercellular spaces between desmosomal junctions.

In incisions that had penetrated the epithelial layer the wash of congealed 'lava' appeared as a stratified mass of alternating high and low electron density (Fig. 5d). The denser of these two components looked like a highly convoluted sheet of coagulated cell debris, but was far coarser in substructure than the homogeneous ribbons of pseudomembranes seen in areas of argon fluoride irradiation. The pale strata were merely the spaces between sheets, but had acquired an apparent textural organisation because of the aggregation of flocculent material breaking off from the edges of the dense laminae. Close to the margins of these wounds the debris was opposed to vacuolated cell ghosts similar in distribution and morphology to those seen in superficial ablations. At the distal border of the 'lava zone' debris coated the surface of normal cells.

\section{Conventional incisions}

In contrast to laser induced ablations, which are essentially a no-touch technique, with conventional

Fig. 4 Transmission electron micrographs of rabbit corneal epithelial cells incised by (a) an argon fluoride excimer laser; (b) a krypton fluoride excimer laser; (c) a Micra diamond knife; and (d) a Sharpoint steel blade. The pseudomembrane (arrowed) bounding the incised cells in (a) seems to contain the cell contents within cleaved cell fragments. This is in contrast to cells incised with either of the conventional cutting devices, where contents are evulsed from the cleaved surfaces (c) (d). In superficial damage induced by the krypton fluoride laser (b) a compacted surface layer is apparent (arrowed) overlying a zone of vacuolated cells. The bar markers are (a), (b), (d) $5 \mu \mathrm{m}$ and (c) $2 \mu \mathrm{m}$.

Fig. 5 Scanning (a) (b) (c) and transmission (d) electron micrographs of rabbit corneal epithelial cells ablated by a krypton fluoride excimer laser. The problems of eye movements ar seen in (a), where a deep (open arrow) and superficial (closed arrow) pair of parallel incisions occur as a result of target movement during the pulse train of the laser exposure. The lava-like smooth surfaced debris (arrowed) is shown in (b) and (c) and its lamina substructure is demonstrated in (d). The bar markers are (a) (b) $100 \mu \mathrm{m}$, (c) $50 \mu \mathrm{m}$ and (d) $2 \mu \mathrm{m}$. 

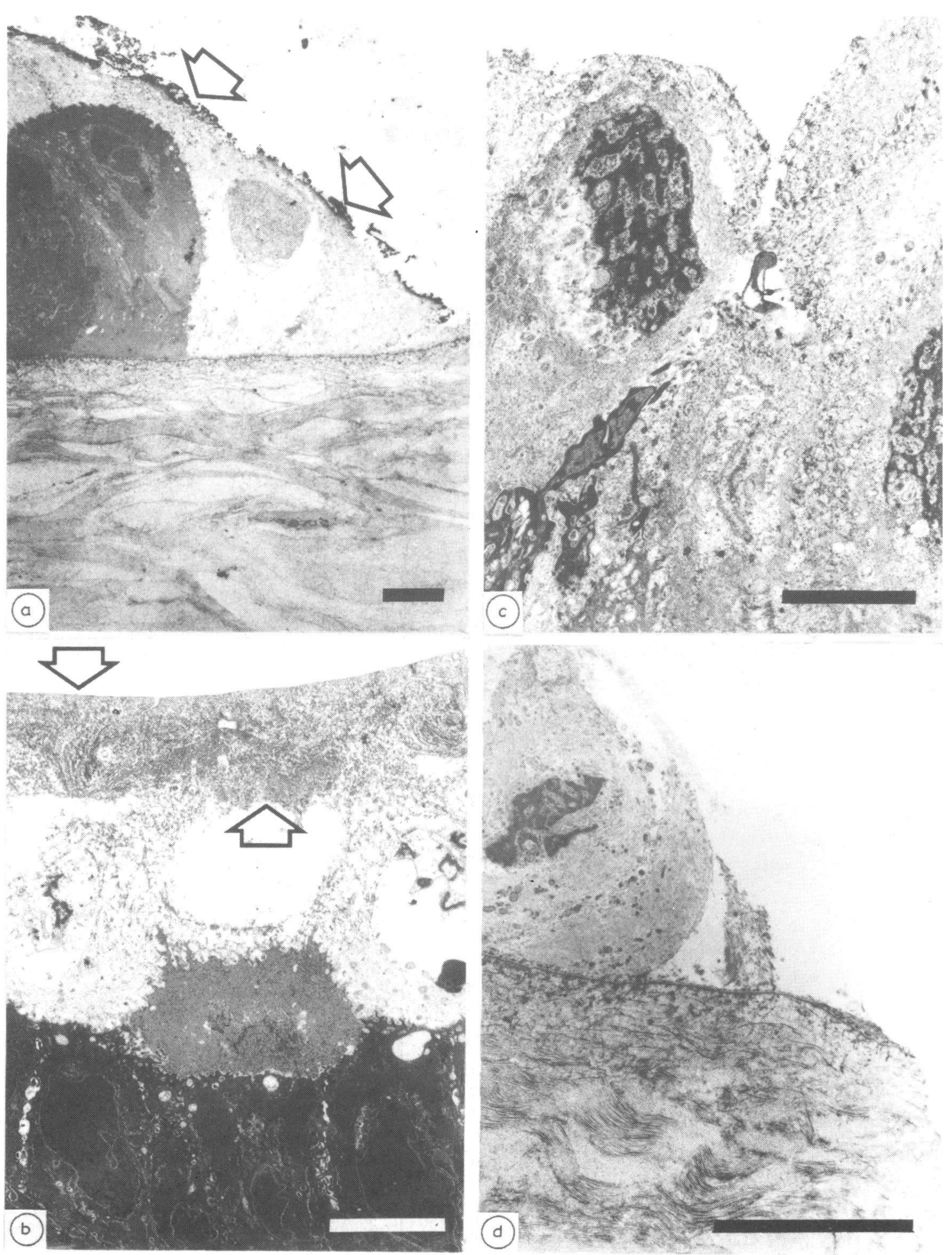

Fig. 4 

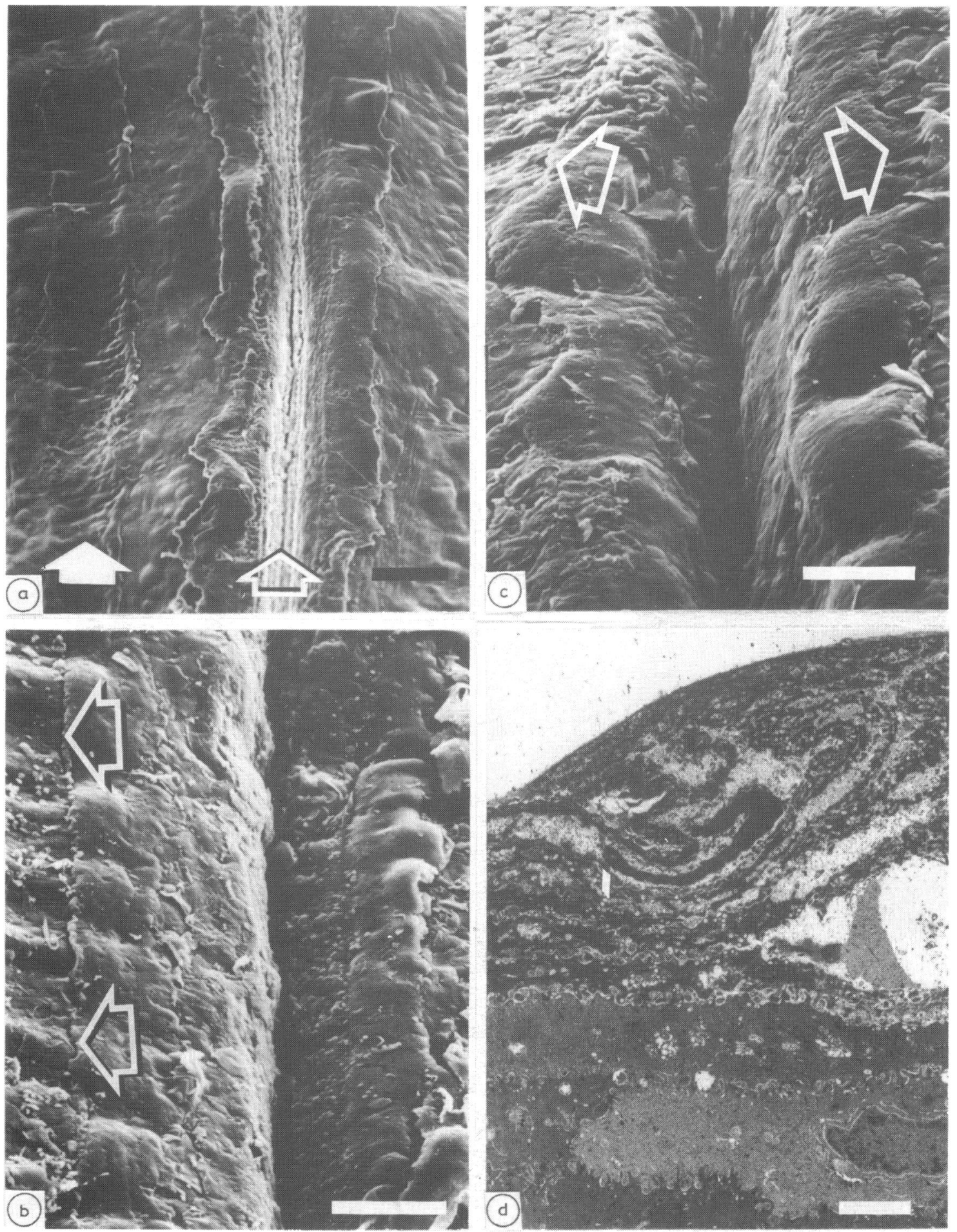

Fig. 5 
surgery there is a degree of tactile feedback resulting from tissue drag as the cutting instrument is moved. The drag factor was noticeably higher with steel blades than with diamond knives, and eyes cut with the former required a greater degree of counter traction or fixation during cutting.

Diamond. Incisions produced by the Micra knife caused virtually no traction distortion to the surface cells of the epithelium (Fig. 6). SEM showed that the borders of such incisions either were lined by the virtually undisturbed but hemisected components of surface cells, or were bounded by normal epithelial cells that had migrated over the lip of the microcrevasse induced by the passage of the instrument (Fig. 6b, c).

In TEM preparations all diamond knife incisions were confined to within one cell diameter in width. Usually in such preparations a slight furrow was seen in the epithelial surface, and beneath this epithelial cells were displaced towards the stroma (Fig. 6d). In some incisions epithelial cell debris was displaced to lie within the confines of the incision in this deeper layer.

Steel. Incisions induced by the Sharpoint microsurgical steel blade were always much wider than those induced by the diamond and were usually $20 \mu \mathrm{m}$ to $65 \mu \mathrm{m}$ in width at the corneal surface (Fig. 7). Although these particular blades are ground on both aspects, the resultant wounds tended to be asymetric V-shaped troughs whose most angular wall corresponded to the laterality or handedness of the surgeon (Fig. 7a, b).

The role of tissue resistance in relation to cuts produced by steel blades was clearly demonstrated in SEM preparations where angular folds or microstress lines were seen distorting the surface cells for some distance on either side of the wound (Fig. 7c). The angles at which the stress lines ran in relation to any given incision varied with the depth of the incision, the magnitude of the applied pressure, and the speed of traverse of the blade through the tissue. In general, increase in any or all of these factors resulted both in an increasing frequency of folds and in the acuteness of the angle they made with the line of the incision.

Sections through wounds induced by steel blades showed significant damage on both margins, with epithelial cells being disrupted and torn (Fig. 7d). Cleaved cells immediately adjacent to the incision displayed a diffuse zone of subcellular debris avulsed from the torn surface. In many instances the basal cells bordering the cleft were dislodged from their basal membrane and compressed both upwards and outwards from the line of the incision. This compression or contusion injury extended to some four or five cells in width on both aspects of the cut surfaces.

\section{THE STROMA}

Argon fluoride laser irradiation (193 $\mathrm{nm})$

SEM preparations demonstrated the preservation of the focal nature of the ablative process even at the deepest layers of the stroma some $250 \mu \mathrm{m}$ from the epithelial surface. All incisions resulted in an overall swelling of the stroma, although the degree of separation between individual lamellae in some SEM preparations was probably an artefact associated with the critical-point drying process. In penetrating incisions the marginal portions of the most superficial lamellae on both the internal and external aspects of the stroma converged to round off the respective borders of the ablated areas.

In LM and TEM the pseudomembranes seen bounding the ablated edges of epithelial cells were again present and in this location appeared as densely staining lines bordering the irradiated areas and running across the axis of the stromal lamellae (Fig. $3 c, d)$. In penetrating incisions where collapse of the trough had resulted in juxtaposition of the respective edges this pseudomembrane zone became as narrow as $150-300 \mathrm{~nm}$ in width (Fig. 8a). As in the epithelium, this zone had two components with a highly electron dense surface condensation $20-100$ $\mathrm{nm}$, and a less dense intralamellar portion 60-200 $\mathrm{nm}$. The intralamellar condensation seemed to be predominantly associated with changes located within the glycoprotein matrix of the lamellae as changes in the staining properties of lamellar collagen was rarely observed. In some few cases individual collagen fibres were observed to have passed out of lamellae and to lie axially within the incision. In those exposures that involved the incision of conjunctival blood vessels blood products, including red and white cells and fibrin, were observed in association with the edges of the troughs throughout their corneal portions. The presence of these blood components to some extent complicated the analysis of changes observed in the border zones, and made it

Fig. 6 Light (a) and electron (b) (c) (d) micrographs of incisions in the epithelial cells of a rabbit cornea, created by a Micra diamond knife. The path of the incision in the transmission electron micrograph (d) is arrowed. The bar markers are (a) (b) $50 \mu \mathrm{m}$, (c) $10 \mu \mathrm{m}$ and (d) $2 \cdot 5 \mu \mathrm{m}$.

Fig. 7 Light (a) and electron (b) (c) (d) micrographs of incisions in the epithelial cells of a rabbit cornea, induced by a Sharpoint steel blade. The asymmetry of the kerfs produced by this treatment is seen in (a) and (b) and showed the laterality of the surgeon. The stress lines induced in tissue by even new steel blades can be seen (arrowed) in (c). The bar markers are (a) (b) $50 \mu \mathrm{m}$, (c) $10 \mu \mathrm{m}$, and (d) $l \mu \mathrm{m}$. 

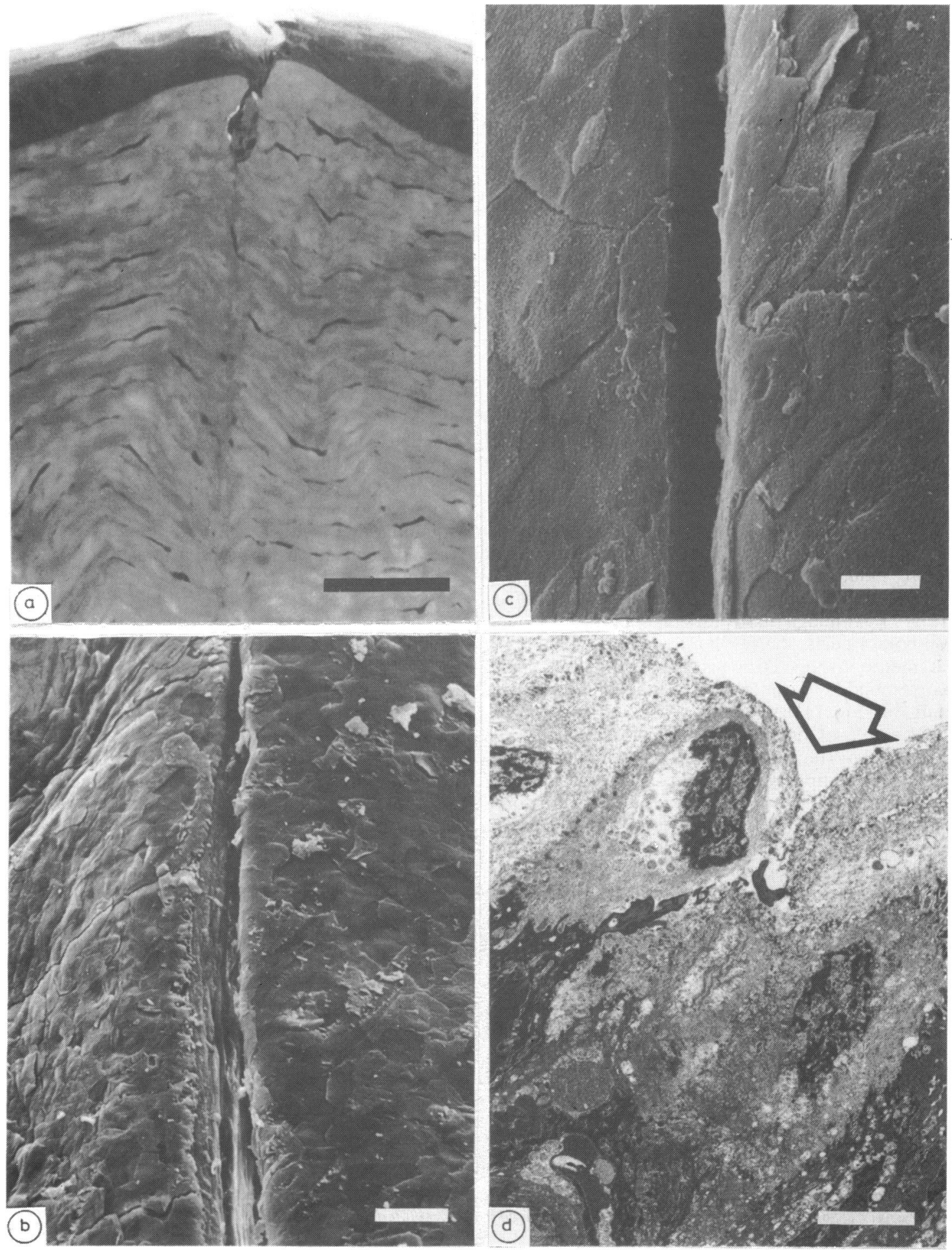

Fig. 6 

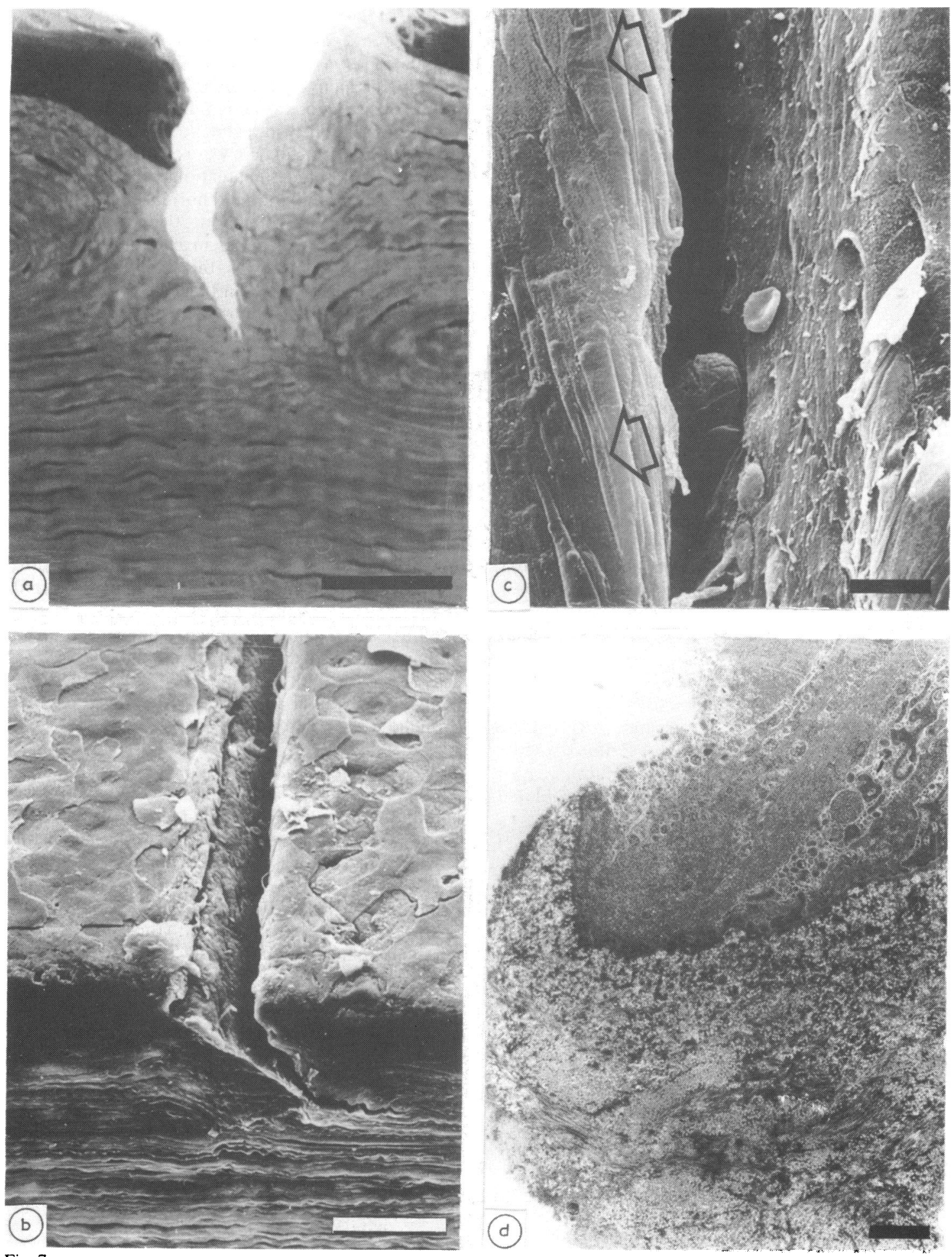

Fig. 7 
difficult to assign such changes to those induced as a primary response to laser radiation and those that occurred as secondary tissue reactions or repair processes. One notable observation was that, wherever leucocytes had attached themselves to the walls of the troughs, the electron dense extralammellar component of the pseudomembrane was always absent.

All incised lamellae were swollen to between 2 and $2 \frac{1}{2}$ times that of normal lamellae. The degree of swelling was maximal immediately adjacent to the ablated edge and progressively decreased to become normal some $450-500 \mu \mathrm{m}$ away from the wall of the incision. The individual collagen fibres in the cleaved portion of the lamellae increased in spatial separation to between 60 and $130 \mathrm{~nm}$ centre to centre as opposed to 45 to $60 \mathrm{~nm}$ in normal regions. In some lamellae the fibres at the ablated ends splayed or diverged, while in others there was a convergence or pinching together. These observations presumably give some indication of the states of tension that existed in any given lamella when it was cut, but in penetrating incisions the final picture may well have been modified by the two ablated ends moving against each other. The movement between the two portions of an individual lamella cleaved by ablation was frequently identified by the acute changes in orientation of collagen fibres in a specific stratum on either side of the incision.

\section{Krypton fluoride laser irradiation $(248 \mathrm{~nm})$}

The first and most striking observation was that the line of ablation was no longer the confined rigidly linear plane seen at $193 \mathrm{~nm}$ but a meandering ragged edged gash. Secondly, the borders of the ablated zone were not sealed by pseudomembranes.

In TEM preparations the cleft within the zone of ablation was filled with a flocculent, relatively electron dense exudate containing fragments of collagen fibrils and isolated membrane profiles (Fig. $8 b)$. The flocculent condensate was most compact within the central portion of the cleft, but then merged to give rise to a less compacted and less electron dense zone adjacent to each margin. In turn the pale zone was bordered externally by a morphologically distinctive dark band $2 \mu \mathrm{m}$ to $3 \mu \mathrm{m}$ in width, consisting of swollen and denatured collagen fibres (Fig. 8b). The width and the substructure of the band of denatured collagen was constant throughout the entire depth of all the ablations. On entering the distal aspect of the dark band normal collagen fibres doubled in diameter from about $30 \mathrm{~nm}$ to $60 \mathrm{~nm}$, and at the same time an axial change in fibre direction occured (Fig. 8b). It was this band of swollen, denatured, disorientated, and splayed collagen fibres that gave such a ragged edged appearance. As with $193 \mathrm{~nm}$ irradiations, all incised lamellae were swollen immediately adjacent to the ablated edges, but at this wavelength other disturbances were also noted in a zone extending some 15 to $20 \mu \mathrm{m}$ from the ablated edge. These ranged from areas of undulating or extremely disorientated collagen fibres, to isolated foci of swollen and electron dense elements like those in the dark band. Where keratocytes had been cleaved, the isolated remnants assumed an extreme electron density at the distal margin of the dark zone, and this was maintained up to $10 \mu \mathrm{m}$ into unirradiated tissue. In such damaged cells no organelles could be determined within the denatured cytoplasm, and in many cases vacuolation occurred around the cell remnants and displaced the adjacent lamellae.

As in argon fluoride exposures, where incisions involved the limbal vessels, blood cells were seen throughout the ablated cleft.

\section{Conventional incisions}

Diamond. Stromal incisions executed with the diamond knife displayed minimal disturbance to adjacent tissues. Remote from the surface layers the line of any incision was difficult to detect, and in some cases was only disclosed by dislocations in the strata formation of lamellae. In virtually all incisions the cut edges were closely associated, with the exception of a few subepithelial lamellae. In such superficial clefts a

Fig. 8 Transmission electron micrographs of the stromal aspects of incisions through rabbit corneas induced by (a) an argon fluoride excimer laser; (b) a krypton fluoride excimer laser; (c) a Micra diamond knife; and (d) a Sharpoint steel blade. (a) Shows two distant changes in relation to this incision, an extralamellar zone of high electron density or pseudomembrane (open arrows), and a somewhat larger but less electron dense intralamellar zone (closed arrows). (b) Shows more diffuse and extensive changes, with the cleft being full of flocculent deposits and bordered by the dark zone (arrowed) of swollen and disorientated collagen fibres. (c) The course of this incision (arrowed) is difficult to trace, as the edges of the wounds induced by diamond knife routinely closed. (d) Stromal incisions induced by steel blades always contained isolated fragments of collagen fibres (arrowed). The bar markers are $1 \mu \mathrm{m}$.

Fig. 9 Scanning electron micrographs of the endothelial cell surface of rabbit corneas in areas colinear with deep stromal incisions induced by (a) an argon fluoride and (b, c, d) a krypton fluoride excimer laser. In (a) the eye remained in situ for about 30 minutes after exposure, and pseudopodia are beginning to emerge from the endothelial cells whose borders are adjacent to the region of cell loss. A spectrum of change ranging from badly damaged cells (b) (c) to areas of cell loss (d) was a common observation with deep incisions at $248 \mathrm{~nm}$. The bar markers are (a) $25 \mu \mathrm{m}$, (b) $250 \mu \mathrm{m}$, (c) (d) $50 \mu \mathrm{m}$. 


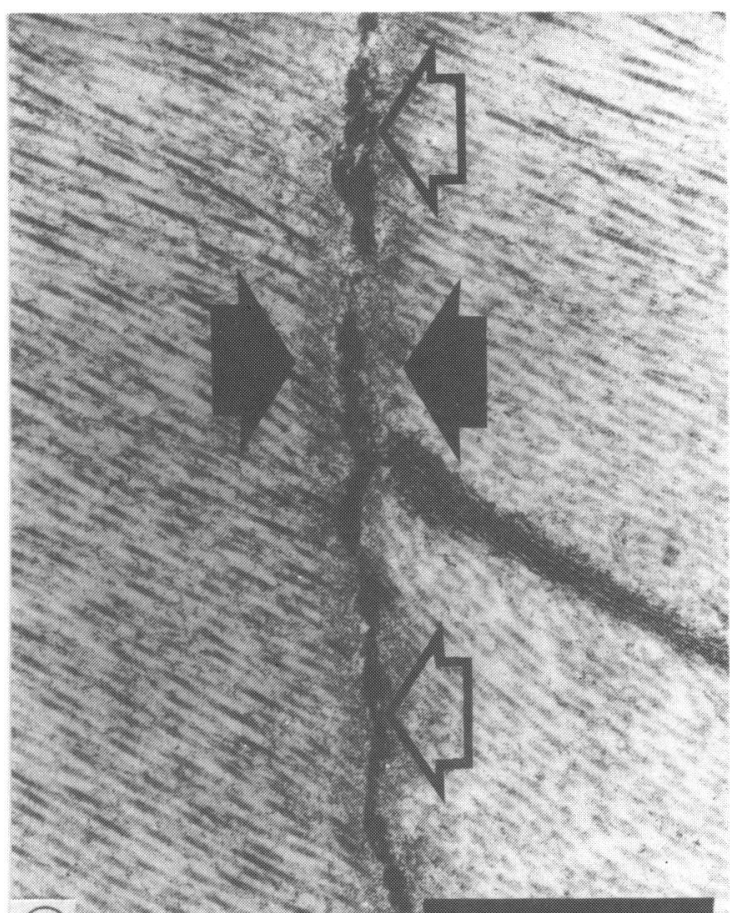

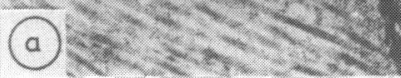

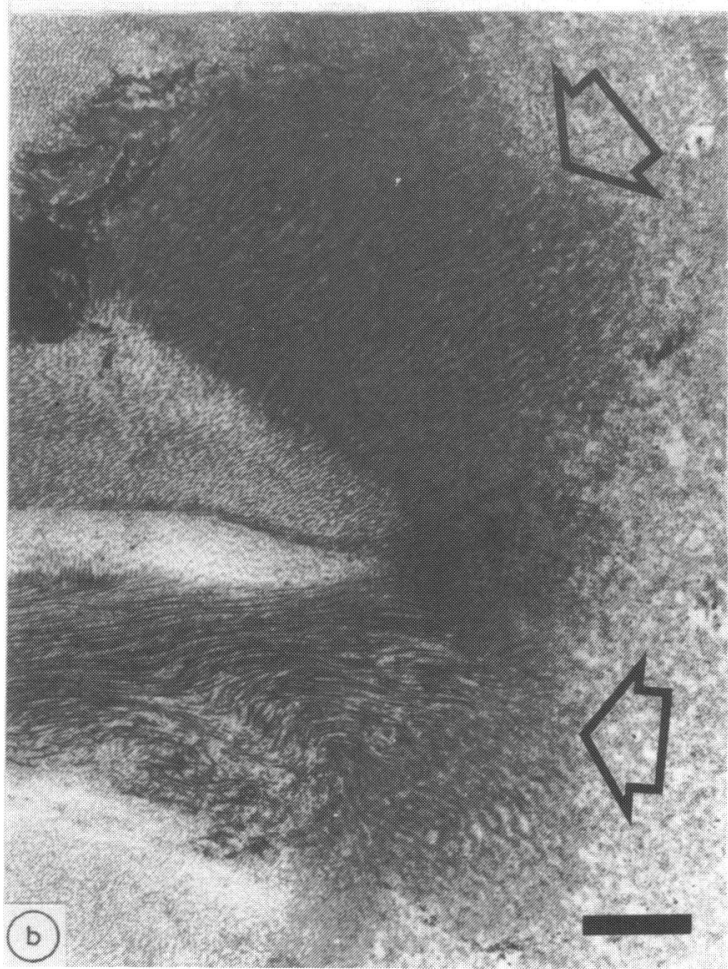

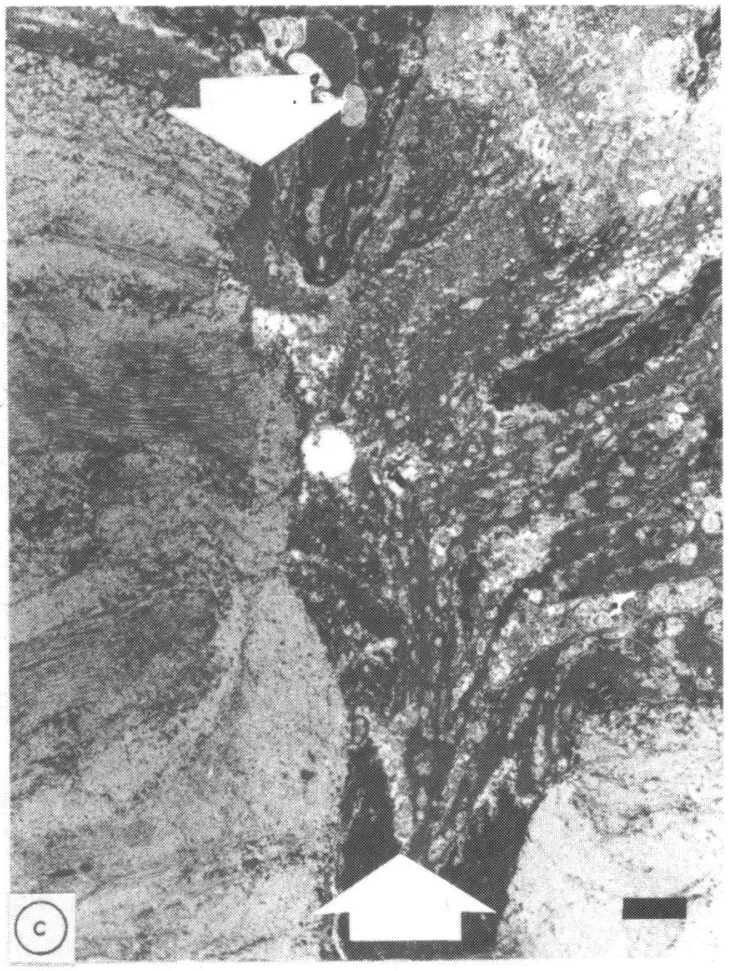

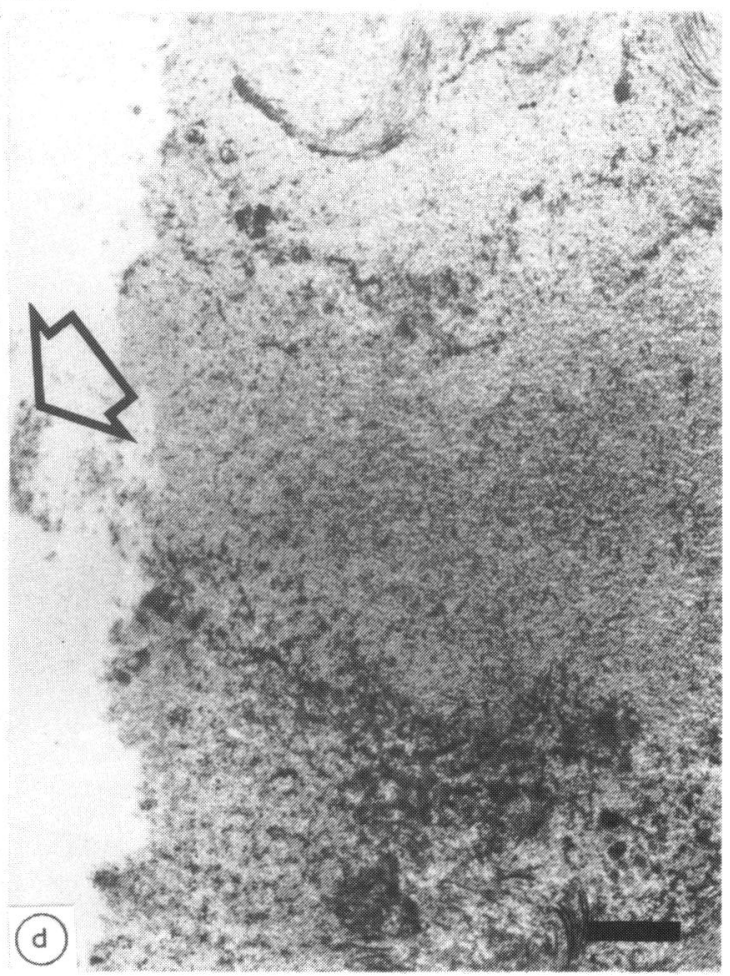

四

(

응

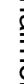

声

뭉

$\overrightarrow{0}$

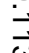

逢

응.

기

i

文

윽

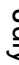

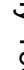

@

인

ฏ

8

○

용

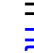

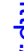

흥

웅

ํํำ

을

욕

글

N

N

W

문

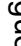

c

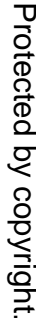



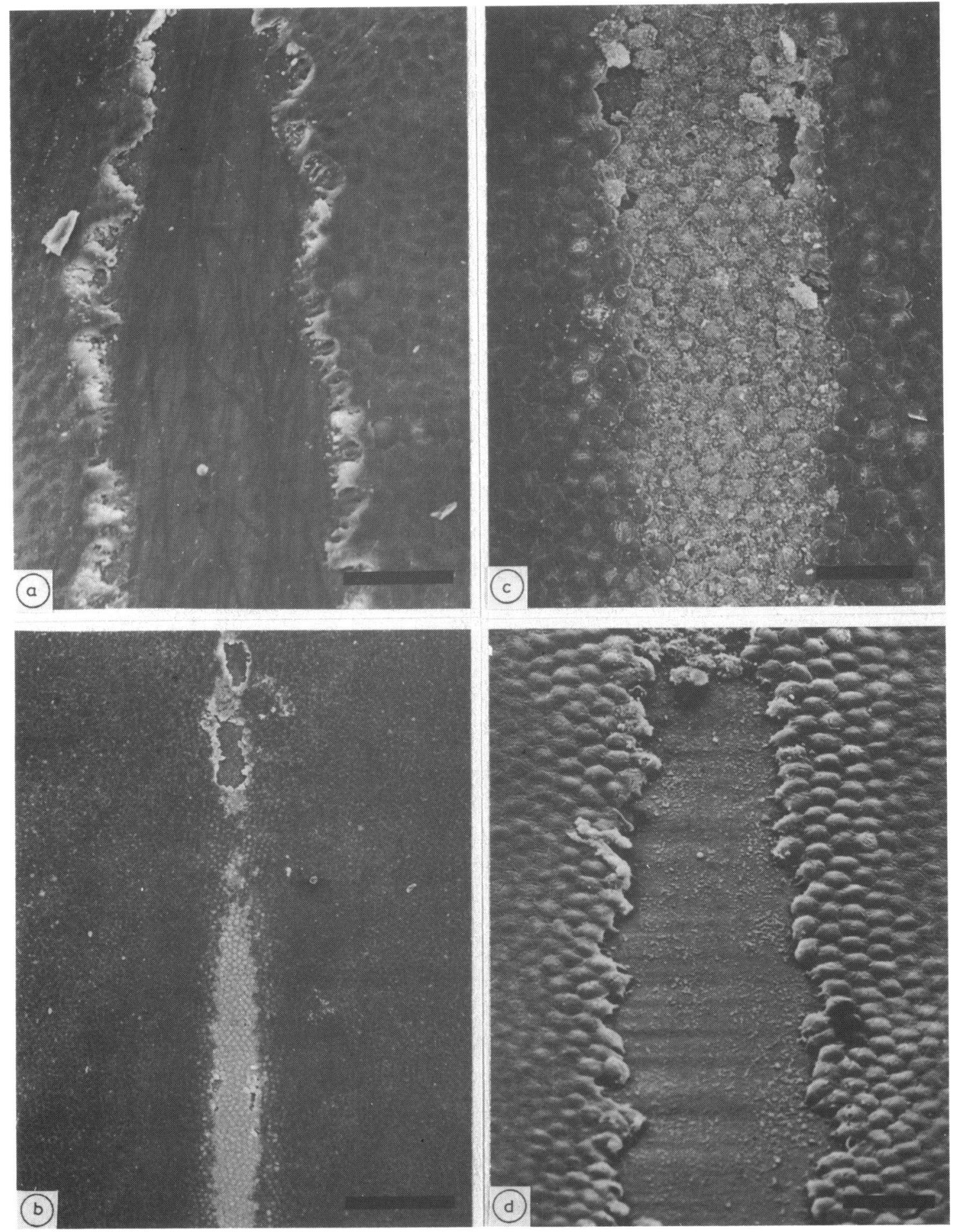

Fig. 9

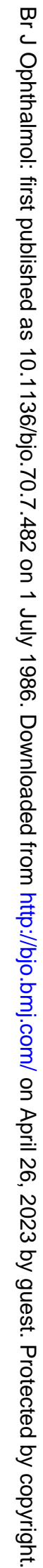


similar electron opaque exudate to that seen in krypton fluoride ablations was apparent, but the substructure differed in that only a slight increase in electron density occured adjacent to the cleaved stromal edges (Fig. 8c).

No changes in diameter, staining properties, or orientation were determined in the collagen fibres of transected lamellae, although in some cases the fibres splayed slightly at the plane of incision.

Steel. The asymetric V-shaped grooves characteristic of incisions induced by steel blades, did not contain any electron opaque or flocculate material. In all such preparations the only content of the clefts was dislocated collagen fibres, either isolated or in bundles (Fig. 8d). On both edges of all steel blade incisions the cleaved lamellae were displaced towards the posterior surface of the cornea. Like incisions induced by the diamond knife, damage to the lamellae was not accompanied by gross changes in the staining properties or dimensions of the collagen fibres involved.

The vertex of clefts produced by steel blades were complex in that there was always evidence of blunt trauma or tissue displacement by splitting. This change in mechanism from cutting to compressional ripping was supported by the observation that steel blade incision ended in fissures extending along the strata between lamellae and at right angles to the axis of the cut.

DESCEMET'S MEMBRANE AND THE ENDOTHELIUM None of the incisions produced with diamond or steel knives were sufficiently deep to damage either of these two layers. However, a surprising result was obtained in relation to non-penetrating ablations by both wavelengths of laser radiation. SEM preparations demonstrated endothelial cell loss along the line of some incisions even when Descemet's membrane had not been severed (Fig. 9). We had too few samples to determine the critical depths at which such loss or spalling of cells began to occur, but from our limited observations the floor of the trough had to be closer to Descemet's membrane than $40 \mu \mathrm{m}$ at 193 $\mathrm{nm}$ and $60 \mu \mathrm{m}$ at $248 \mathrm{~nm}$.

\section{Argon fluoride laser irradiation (193 $\mathrm{nm}$ )}

In ablations closer to Descemet's membrane than $40 \mu \mathrm{m}$, typically Descement's was denuded of cells in linear swathes 5 to $12(100-240 \mu \mathrm{m})$ cells across and whose long axis was coincident with that of the incision (Fig. 9a). The surface topography of endothelial cells bounding this area depended on the time that had expired between irradiation and fixation of the tissue. In those samples fixed within minutes of exposure the boundary cells had relatively sharp angular borders whose geometry seemed to mirror that of lost cells. If eyes were left in situ for longer than 30 minute after irradiation, this topography had changed such that the previously angular borders of the boundary cells had transformed into irregular, long, flat pseudopodia (Fig. 9a).

In sections, linear discontinuities were seen in Descemet's membrane both with and without penetrating damage to the overlying stroma, and in most cases it was relatively easy to discriminate between such radiation induced damage and perturbations due to preparative artefact. In penetrating incisions the ablated margins of Descemet's membrane were sharp and appeared little altered in terms of electron density, and coiled outwards towards the epithelial surface. In a few samples Descemet's membrane had broken as a result of inappropriate handling during processing. These artefacts were distinguished as the endothelial cells in such regions had fissures extending either around their hexagonal cell borders or straight across the cells cytoplasm.

\section{Krypton fluoride laser irradiation $248 \mathrm{~nm}$}

Some endothelial cell lesions at this wavelength were similar to those described at $193 \mathrm{~nm}$ in terms of both morphology and dimensions. In addition some lesions were observed in which rectilinear areas of endothelial cell damage, rather than cell loss, were apparent (Fig. 9b, c). These lesions were of variable length, in excess of hundreds of $\mu \mathrm{m}$, and maximally 5 to 8 cells in width. In SEM preparations affected cells appeared lighter than the normal surrounding endothelial population. On higher power observation damaged cells were flattened, had lost definition in relation to their cell borders, and had their surface membrane covered with spherical particles, presumably debris. In places individual cells or groups of cells were lost from the surface of Descemet's membrane within such lesions, and in these locations debris was present on the surface of the denuded membrane itself (Fig. 9d).

\section{Discussion}

This study is concerned with the acute effects induced in corneal tissues by incising them with a number of different agents.

We employed conventional incising devices in order to establish a data base using our tissue preparation procedures, against which to compare the unknown elements of damage induced by ultraviolet laser irradiation. In reality, although the scalpel has been a fundamental tool in surgery for many centuries, little is known about the physics of cutting tissues when considered at a molecular or atomic level. It is therefore difficult to relate the physical forces required to move the blade of a scalpel 
through biological tissues to the forces that are overcome in pushing disturbed molecules or molecular fragments apart. We do not know if there are preferred lines of cleavage at a cellular level within biological membranes or systems, nor do we know details of the chemical trauma that such molecular cleavage must induce. At a gross level our results confirm those of previous workers, that diamond knives appear to cut tissues ${ }^{10-12}$ whereas steel blades seem to tear them via a shearing action. ${ }^{13-15}$ This difference in mode of operation is related to a number of physical differences in the structure of the two blades. The edge of a diamond blade is formed from a crystaline matrix which is extremely hard, perfectly smooth, and impermeable. The angles of bevel on the blades vary according to preference, but the tips usually end in a slight radius and are maximally $0.1 \mu \mathrm{m}$ in width. When new, diamond knives have cutting edges which display virtually no blemishes. ${ }^{16}$ In contrast, steel blades are relatively soft and have a coarse textured surface that is comparatively porous. The cutting edge of steel blades is usually $1.5 \mu \mathrm{m}$ in width, and even when freshly honed contains many blemishes and imperfections. While the greater tip width is important, surface imperfections on steel blades are the major contributors in increasing tissue resistance or drag factors encountered when making incisions with such devices. In turn, both the perturbations induced in the rate of motion of the blade by such resistance, and the relative movement of compressed tissue within the line of the incision and at right angles to it, cause problems in predetermining the depth of cut at any given point. We and others" have found that it is virtually impossible to incise tissue to a given depth, and therefore this must be a major deficiency in their employment in such procedures as radial keratotomy. ${ }^{1013-15}$

On a cursory examination of the laser induced damage it is clear that a multifactorial induction process must be postulated, as no single damage mechanism could account for both the direct ablative effect in the incisions and the remote loss of endothelial cells beneath the troughs. Each of these two phenomena could result from a single but different damage mechanism, or each may be the product of the interaction of several such mechanisms.

Theoretically the following mechanisms may play a part in the ablation of tissue during the creation of incisions:

(1) Photoablation, or direct photon induced molecular decompensation. ${ }^{67}$

(2) Ultrafast thermal events, or photon-phonon interactions within the adsorption depth of the incident radiation. ${ }^{5}$
In contrast the loss of endothelial cells may be related to:

(1) Fluorescence and scattering from the absorbing volume of tissue, with the production of longer wavelength radiation that could be transmitted to, and absorbed by, deeper tissues. ${ }^{17}$

(2) Resonance induced in the posterior border of the cornea as a result of the pulse repetition frequency.

(3) Acoustic waves generated either by the explosive deposition of energy during ultrashort pulses or as a result of target recoil as tissue is lost from the irradiated surface. ${ }^{1819}$

(4) Shock waves created by supersonic expansions, again related to energy deposition during ultrashort pulses. ${ }^{20-22}$

At a practical level it is extremely difficult to discriminate between the physical processes that may be involved in the ablation of tissue. Indeed so new is this technology in biological applications that we do not even possess accurate information on the transmission characteristics of far ultraviolet radiationdata which are essential for detailed biophysical analysis of mechanisms. So far published data on transmission and absorption coefficients for ocular media in the ultraviolet have been obtained by means of suitably filtered emission from mercury xenon sources. As a result no useful data exist for wavelengths shorter than $250 \mathrm{~nm} .{ }^{2324}$ These studies did generate some useful general findings in that the high optical density of 4, between 200 and $295 \mathrm{~nm}$, can be explained only by assuming a significant role in absorbing this radiation by proteins and collagen; for example, peptide bonds present in the cornea will absorb at $190 \mathrm{~nm}$. This is in direct contrast to absorption of infrared radiation, where water is the principal absorber. ${ }^{25}$ The high absorption, or short penetration depth, of ultraviolet radiation means that transmission figures cannot be determined for the intact cornea-that is, insufficient radiation passes through it to be measured.

Several workers have recently made measurements using frozen sections of corneal tissue, and two sets of data are currently being discussed. Puliofito (personal communication) estimates that the attenuation length in the cornea is about $1 \mu \mathrm{m}$ at $193 \mathrm{~nm}$ and 3 to $5 \mu \mathrm{m}$ at $248 \mathrm{~nm}$. In contrast, Hillenkamp (personal communication) claims measured figures of $3.5 \mu \mathrm{m}$ at $193 \mathrm{~nm}$ and $33 \mu \mathrm{m}$ at $248 \mathrm{~nm}$ respectively.

Observations on the stroma in the present study could give rise to some unfortunate misconceptions, as for example, the lateral spread of tissue damage associated with the ablation process is $300 \mathrm{~nm}$ at $193 \mathrm{~nm}$; and 2 to $3 \mu \mathrm{m}$, the dimension of the dark band, at $248 \mathrm{~nm}$. If such dimensions were assumed to 
be related to the penetration depth of laterally scattered photons, they would seem to offer circumstantial evidence in support of Puliofito's claims. However, such an assumption would be incorrect, as these damage zones do not correspond to the total photon absorption depth but that fraction of the depth at which the fluence is sufficient to cause significant damage. In a recent quantitative study looking at the photochemistry of bond cleavage in both polymethylmethacrylate (PMMA) and collagen induced by irradiation at both 193 and $248 \mathrm{~nm}$, the most conclusive evidence for an underlying mechanism of photoablation has been provided, and the figures of Hillenkamp best fit the experimental data. ${ }^{26}$ In these experiments Srinivasan and his coworkers measured the depth of tissue etched per pulse as a function of the fluence generated by each pulse, and at the same time they chemically analysed the molecular moities generated by the ablation process. Their findings were highly significant and will be fundamental to future work in this field. In summary they have discovered the following:

(1) The etch depth per pulse was 10 times greater at $248 \mathrm{~nm}$ than at $193 \mathrm{~nm}$, which approximately matches the inverse ratio of the absorptivities at the two wavelengths (Hillenkamp's data). This accuracy of dose versus tissue loss or cutting depth has recently been exploited in a series of experiments to test the viability of $193 \mathrm{~nm}$ irradiation in radial keratotomy in human cadaver eyes. ${ }^{27}$

(2) The mass of material ablated per joule of energy absorbed within the ablated volume was similar at both wavelengths.

(3) When the etch depth per pulse was plotted as a function of the fluence of pulses, a similar shaped curve was obtained for each wavelength, and each curve could be subdivided into three regions. In the first part of the slope of the sigmoid curve the fluence is low, and effectively below true ablation, threshold fluence. The second part of the curve rises rapidly and accounts for efficient ablation being a region where 20 to $90 \%$ of the incident photons are absorbed within the ablated volume. Finally, a flattening tail suggests a loss of potency of ablation due to the occurrence of secondary photolytic processes. All of our irradiations were carried out in the true ablation region.

(4) The chemical products of photomolecular decompensation of PMMA are the same at both wavelengths, carbon dioxide and methylmethacrylate (MMA), ${ }^{28}$ but the proportions generated are quite different. ${ }^{26}$ At $193 \mathrm{~nm} 18 \%$ of the ablated polymer is broken up into MMA or oligomers of low molecular weight. In contrast, at $248 \mathrm{~nm}$ less than $1 \%$ appears as MMA, and the predominant products are a mixture of high molecular weight oligomers.
Similar results were obtained with collagen, with fragments of smaller molecular weight being produced by irradiation at the shorter wavelength. This finding is the key to the difference in edge quality seen in cuts throughout the present study.

(5) Debris expelled by irradiations at $193 \mathrm{~nm}$ was in the form of fluffy, cotton-like material, which was in contrast to the fused coalesced masses seen at $248 \mathrm{~nm}$. These findings are confirmed in our study and imply that lower temperatures prevail at the shorter wavelength.

We would support the hypothesis of Srinivasan and his colleagues that excimer lasers induce their beam tissue interactions by photomolecular decompensation. In their thesis it is suggested that the ablation process requires a balance between the photon energy which determines the quantum yield for bond break, and the excess energy of the photon over the bond energy which is then available to expel the products at supersonic velocity. An ultrafast thermal process does not fit the observed kinetics and could not account for the different molecular proportions in the debris generated by the two wavelengths.

The process of photomolecular decompensation may have profound implications with respect to cutting biological tissues, as it seems to cleave organic bonds in a novel fashion. Both the mechanical transients associated with conventional cutting devices like diamond and steel, and thermal disturbances generated by laser photocoagulators, rupture bonds in the electronic ground state and therefore generate large zones of damage by secondary translocation of energy degrading processes. In contrast photoablation involves the electronically excited state of the bonds undergoing cleavage and is highly localised. The 'unzipped' molecules in the pseudomembranes of cells cleaved by irradiation at $193 \mathrm{~nm}$ may result in a sufficiently undisturbed interface on their distal aspect so that the cell remnant can, and clearly does, survive for some time after trauma (Fig. 4a). ${ }^{29}$ This obviously does not happen with diamond or steel incisions, where cleaved cells die immediately, either through loss of their contents expelled through the cut surface or as a result of osmotic problems. Given the importance of chemogradients in inflammatory and healing responses, the focal nature of the ablation process may well result in an increased latency at the beginning of wound healing, both by virtue of the small volume of tissue damaged and the creation of an artificial barrier to diffusion of chemical markers. The pseudomembranes may also present short term physical barriers that limit the access of macrophages.

Having suggested that $193 \mathrm{~nm}$ is the wavelength of choice for further investigation of the surgical role of excimer lasers, and having excepted that tissue 
ablation occurs by a photochemical process, we believe it may be helpful to comment briefly on the safety considerations of such irradiations. At $193 \mathrm{~nm}$ the cornea is virtually opaque and therefore there is no risk to deeper structures. This does not hold for the longer wavelength excimer lasers, because between $308 \mathrm{~nm}$ (xenon chloride) and $350 \mathrm{~nm}$ (xenon fluoride) the cornea transmits significant amounts of the incident radiation. ${ }^{30}$ The xenon chloride excimer laser could be called a 'cataract machine' because at $308 \mathrm{~nm}$ the threshold for lens damage is only about $1 \mathrm{~J} / \mathrm{cm}^{2}$. In the phakic eye only a trace amount of such radiation would reach the retina, but in an aphakic eye this figure rises to $50 \%$, and it should be remembered $308 \mathrm{~nm}$ is near the peak of the action spectrum for solar UV induced carcinogenesis of the skin. The mutagenic effects of ultraviolet radiation have received much attention, and at present the most harmful wavelengths are considered to be those around the peak absorption of DNA, about $280 \mathrm{~nm} .{ }^{30}$ It is also interesting to note in this context that the minimum irradiance thresholds for photokeratitis are between 3 and $4 \mathrm{~mJ} / \mathrm{cm}^{2}$ and occur at $270 \mathrm{~nm} .{ }^{30}$

In the present study doses of some hundreds of $\mathrm{mJ} / \mathrm{cm}^{2}$ were used but at a wavelength which the best evidence suggests is outside the mutagenic zone, and whose absorption depth limits penetration almost to the zone of ablation. Obviously we will be examining this question in more detail in the future, but currently we do not envisage major problems with mutagenesis.

The loss or spalling of endothelial cells beneath the line of irradiation is clearly a matter of concern in relation to potential surgical applications, and further experiments are under way at a variety of energy fluences to determine the critical ablation depth and dose configuration at which this complication arises (Fig. 9). Our current observations based on the geometry and dimensions of the area of cell loss suggest that these cells are compromised by mechanical (shock or acoustic) waves dissipating their energy at an interface of mismatch of acoustic impedance. ${ }^{3132}$ This concept is supported by our observations that endothelial cell damage is greater at $248 \mathrm{~nm}$ and occurs at this wavelength when erosion depths are farther from Descemet's membrane than when troughs are created by $193 \mathrm{~nm}$ radiation. This finding is significant because at the longer wavelength more tissue is eroded per pulse and the resultant mechanical waves are larger. ${ }^{26}$ We do not consider the fluorescence induced by absorption of ultraviolet radiation within the ablation zone to have a significant role in endothelial cell loss.

In conclusion we feel that excimer laser radiation at $193 \mathrm{~nm}$ may have a future in microsurgery of the eye. It seems to ablate tissue by a novel photo- chemical process whose parameters can be controlled to incise tissue to precise depths with submicron accuracy. It now awaits further study to determine if any problems exist in relation to wound healing or mutagenesis.

We thank Mr B Parmar for technical assistance and Mrs V Borrow and Mrs C White for secretarial help. We are indebted to Fight for Sight, the Royal National Institute for the Blind, and the Wellcome Trust for financial support, and to Lamda Physik for use of the laser.

\section{References}

1 Hecht J. Excimer laser update. Laser and Applications 1983; 2: 43-9.

2 Srinivasan R, Mayne-Banton V. Self-developing photoetching of poly (ethylene teraphthalate) films by far UV excimer laser radiation. Appl phys letts 1982; 41: 576-8.

3 Deutsch TF, Geis MW. Self-developing UV photoresist using excimer laser exposure. J Appl Phys 1983; 54: 7201-4.

4 Rice S, Jain K. Direct high-resolution excimer laser photoetching. Appl Phys 1984; A33: 195-8.

5 Andrew JE, Dyer PE, Forster D, Key PH. Direct etching of polymeric materials using XeCL laser. Appl Phys letts 1983; 43: 717-9.

6 Scrinivasan R, Leigh WJ. Ablative photodecomposition: action of far-ultraviolet $(193 \mathrm{~nm}$ ) laser radiation on poly (ethylene terephthalate) films. J Am Chem Soc 1982; 104: 6784-5.

7 Srinivasan R. Kinetics of the ablative photodecomposition of organic polymers in the far ultraviolet $(193 \mathrm{~nm})$. J Vac Sci Technol B 1983; 1: 923-6.

8 Srinivasan R, Wynne JJ, Blum SE. Personal communication and reported in Trokel SL, Srinivasan R, Braren B. Excimer laser surgery of the cornea. Am J Ophthalmol 1983; 96: 710-5.

9 Trokel SL, Srinivasan R, Braren B. Excimer laser surgery of the cornea. Am J Ophthalmol 1983; 96: 710-5.

10 Yamaguchi T, Asbell PA, Ostrick M, Safir A, Kissling GE, Kaufman HE. Endothelial damage in monkey after radial keratotomy performed with a diamond blade. Arch Ophthalmol 1984; 102: 765-9.

11 Unterman SR, Rowsey JJ. Diamond knife corneal incisions. Ophthalmic Surg 1984; 15: 199-202.

12 Galbavy EJ. Use of diamond knives in ocular surgery. Ophthalmic Surg 1984; 15: 203-5.

13 Yamaguchi T, Kaufman HE, Fukushima A, Safir A, Asbell PA. Histologic and electron microscopic assessment of endothelial damage produced by anterior radial keratotomy in the monkey cornea. Am J Ophthalmol 1981; 92: 313-27.

14 Yamaguchi T, Polack FM, Kaufman HE. Endothelial damage after anterior radial keratotomy: an electron microscopic study of rabbit cornea. Arch Ophthalmol 1981; 99: 2151-8.

15 Stainer GA, Shaw EL, Binder PS, Zavalia EY, Akers P. Histopathology of a case of radial keratotomy. Arch Ophthalmol 1982; 100: 1473-7.

16 Rowsey JJ, Balyeat HD, Yeisley KP. Diamond knive. Ophthalmic Surg 1982; 13: 279-82.

17 Pataki A, Meier-Ruge W, Wiederhold KH, Remy E. The laser micro beam as a tool for tissue sampling in biochemistry. Laser and Electro-Optik 1978; 1: 14-6.

18 Marshall J. Thermal and mechanical mechanisms in laser damage to the retina. Invest Ophthalmol Vis Sci 1970; 9: 97-115.

19 Mainster MA, Sliney DH, Belcher CD, Buzney SM. Laser photodisruptors; damage mechanisms, instrument design and safety. Ophthalmology (Rochester) 1983; 90: 973-91.

20 Zel'dovich YB, Raizer YB. Physics of shock waves and high temperature hydrodynamic phenomena. New York, London: Academic Press, 1966. 
21 Steinert RF, Puliafito CA, Trokel S. Plasma formation and shielding by three ophthalmic neodymium-YAG lasers. $A m J$ Ophthalmol 1983; 96: 427-34.

22 Steinert RF, Puliafito CA, Kittrell C. Plasma shielding by Q-switched and mode-locked Nd-YAG lasers. Ophthalmology (Rochester) 1983; 90: 1003-6.

23 Pitts DG, Parr WH. Ocular ultraviolet effects from $295 \mathrm{~nm}$ to $335 \mathrm{~nm}$ in the rabbit eye. Department of Health Education and Welfare, National Institute of Occupational Safety and Health, Report No. 77-130: 1976.

24 Maher EF. Transmission and absorption coefficients for ocular media of the rhesus monkey. USAF School of Aerospace medicine. Report SAM-TR-78-32: 1976.

25 Wolbarsht ML. Laser surgery: $\mathrm{CO}_{2}$ or HF. IEEE J Quantum Electronics in press.

26 Srinivasan R, Braren B, Seeger DE, Trokel S, Krue RR. Photochemical cleavage of organic solids: details of the ultraviolet laser ablation of two organic polymers as $193 \mathrm{~nm}$ and $248 \mathrm{~nm}$. J Am Chem Soc in press.
27 Cotliar AM, Schubert HD, Mandel ER, Trokel SL. Excimer laser radial keratotomy. Ophthalmology (Rochester) 1985; 92: 206-8.

28 Davis GM, Gower MC, Fotakis C, Efthimiopoulis T, Argyrakis P. Spectroscopic studies of ArF laser ablation of PMMA. Appl Phys $B$ in press.

29 Marshall J, Trokel S, Rothery S, Schubert H. An ultrastructural study of corneal incisions induced by an excimer laser at $193 \mathrm{~nm}$. Ophthalmology (Rochester) in press.

30 Sliney DH, Wolbarsht ML. Safety with lasers and other optical sources: a comprehensive handbook. New York: Plenum, 1980.

31 Olson LE, Marshall J, Rice NSC, Andrews R. The effects of ultra sound on the corneal endothelium. I. The Acute Lesion. $\mathrm{Br}$ J Ophthalmol 1978; 62: 134-44.

32 Olson LE, Marshall J, Rice NSC, Andrews R. Effects of ultrasound on the corneal endothelium. II. The endothelial repair process. Br J Ophthalmol 1978; 62: 145-54.

Accepted for publication 15 October 1985. 